\title{
Etnonacionalismo: o MAS e a formação do estado plurinacional boliviano
}

\author{
Ethnonationalism: the MAS and the building of the bolivian plurinational state
}

\author{
Gabriel Fernandes Rocha Guimarães* \\ Doutorando em Ciência Política, Universidade Federal de \\ Minas Gerais - UFMG, Rua Samuel Pereira, 192, apto. \\ 201, Bairro Anchieta, Belo Horizonte, MG, Brasil \\ e-mail: gabrielfrg@bol.com.br \\ *autor correspondente
}

Recebido: 02/05/2012

Aceito: 07/06/2012
RESUMO Este artigo se propõe a analisar como o MAS (Movimento ao Socialismo) foi capaz de articular uma série de demandas étnicas e regionais que vinham cindindo a nação boliviana desde algum tempo. O MAS de Evo Morales, através da última constituição aprovada em 2009, foi capaz de trazer ao jogo político e democrático as demandas oriundas de variados nichos étnicos indígena-camponeses, sendo representados, principalmente, pelas organizações indígenas da região andina, embora também por diversos grupos da região amazônica e do chaco. Através de um sistema de descentralização por vias departamentais e pelas autonomias municipais indígenas, o MAS foi capaz de representar os diversos grupos étnicos em um mesmo pólo ideológico mantendo a unidade nacional.

PALAVRaS-ChaVe Etnicidade; Construção do estado; Autonomias; Pluri-nacionalidades.

ABSTRACT This article intends to analyse how MAS (Movement towards Socialism) was prone to hinge a series of ethnic and regional demands, which were splitting the bolivian nation for some time already. Evos Morales's MAS through the last constitution, approved in 2009, was able to bring to the political and democratic arena the demands from varied ethnic Indigenous-peasant niches, represented mainly by indigenous organizations from Andean region, although also by diverse groups from the amazon and chaco regions. Through a decentralized system by indigenous cantons, MAS could enclose the diverse ethnic groups in a same ideological pole and by this, keep the national unity.

KEYWORDS Ethnicity; State-building; Autonomies;

Pluri-nationalities. 


\section{Introdução}

Nas últimas eleições presidenciais, em janeiro de 2010, a Bolívia viu eleger-se pela segunda vez o Presidente Evo Morales Ayma do Movimento ao Socialismo-Instrumento Político para a Soberania dos Povos (MAS-IPSP). Morales venceu em seis dos nove departamentos bolivianos, tendo sido derrotado apenas em Beni, Pando e Santa Cruz, por Manfred Reyes-Villa, do Plan Progreso para Bolivia-Convergencia Nacional (PPB-CN). Em seguida, obtiveram maior percentual de votação Samuel Doria Medina da Unidade Nacional (UN) e René Joaquino da Alianza Social (AZ). Embora o projeto autonômico sustentado pelos Departamentos orientais tenha sido aprovado, o triunfo do governo em Tarija e Chuquisaca fragmentou a coalizão política dos prefeitos da chamada "meia-lua", amenizando parcialmente a polarização "ocidente $\times$ oriente".

Às eleições, somou-se a aprovação, via referendo, de dois modelos autonômicos discutidos e debatidos desde o início da primeira década do século XXI: as autonomias indígeno-camponesas e as cívicodepartamentais. A autonomia departamental foi aprovada em todos os departamentos, inclusive naqueles situados fora da "meia-lua". O "sim" recebeu $82 \%$ dos votos em Chuquisaca, 78\% em Potosí, 78\% em Cochabamba, $77 \%$ em La Paz e 75\% em Oruro. Nos quatro departamentos da "meia-lua" não houve votação sobre esse tema, pois todos já haviam aprovado a autonomia no polêmico referendo de 2006.

Os departamentos que antes rechaçavam o modelo autonômico proposto pelos cívico-departamentais acabaram aderindo à proposta assimilada pela Constituição. A mudança pode ser explicada, em parte, pelo fato do próprio governo de Evo Morales ter recuado na suas posições iniciais e absorvido parte das demandas da oposição como uma estratégia para diminuir a tensão política desatada entre os dois pólos (departamentos da "media luna" versus departamentos das terras altas e vales centrais) e, sobretudo, porque a autonomia foi bandeira dos movimentos sociais que eclodiram indistintamente em ambas as regiões e que a incorporaram nas suas agendas já na década de oitenta.

Do mesmo modo, as autonomias indígenacamponesas foram aprovadas no mesmo referendum. O texto aprovado na ocasião estabelece, no artigo 2, que os municípios indígenas (instâncias administrativas diferenciadas dos outros municípios) têm direito

\footnotetext{
A "meia-lua" é a região composta pelos departamentos da região oriental boliviana, sobretudo: Santa Cruz, Beni, Pando e Tarija. Deve-se lembrar que a Bolívia é, tradicionalmente um estado de molde unitário, e divido em nove departamentos.
}

a administrar-se de acordo a seus ordenamentos jurídicos próprios baseados em "usos e costumes":

Dada a existência pré-colonial das nações e povos indígenas originário-campesinos e seu domínio ancestral sobre os territórios, se garante sua livre determinação no marco da unidade do Estado, que consiste em seu direito à autonomia, ao autogoverno, à sua cultura, ao reconhecimento de suas instituições e à consolidação de suas entidades territoriais, conforme a esta Constituição e à Lei. (Bolívia, 2009)

Dos 12 municípios onde houve votação ${ }^{2}$ por autonomias indígenas, 11 optaram pelo "sim". Apenas o município Curahuara de Carangas decidiu pelo "não", o que mostra que mesmo nas comunidades indígenas não há necessariamente consenso acerca do tema, talvez, em parte, porque as parcelas de originários já expostos e adaptados a padrões mais modernos e urbanos de vida, consideram que seus interesses estariam melhor servidos fora do padrão autonômico. Veja-se o Quadro 1.

Seja como for, os tipos de demandas autonômicas que tensionaram a política boliviana por quase duas décadas foram finalmente incorporados pela Carta aprovada em janeiro de 2009. Mesmo assim, o corolário constitucional não significa o fim dos dilemas políticos na Bolívia e a possibilidade do processo desaguar na consolidação de uma nova hegemonia fechada, mesmo que de ampla base popular, não pode ser descartada. Porém, até o momento, o alto nível de inclusão e de competição política, assim como a diversidade de interesses contemplados pela nova Constituição, abre a possibilidade do regime boliviano se aproximar de uma configuração poliárquica.

O empate verificado entre os diversos focos reivindicatórios (os diversos grupos indígenacamponeses e os cívico-departamentais, estes não tendo sido analisados neste artigo), assim como a condução política do processo por parte do MAS, fizeram com que a exacerbada polarização que se configurou na constituinte não redundasse no seu fracasso, ou mesmo em guerra civil. A nova Constituição foi elaborada sob forte influência de grupos ligados aos movimentos autonômicos indígeno-camponeses e do partido que hoje dá sustentação ao governo. O MAS representa um, talvez instável, amálgama de interesses que perpassam diversas classes e esferas da sociedade boliviana, desde grupos indígenas e camponeses fortemente organizados, setores operários

\footnotetext{
Muitos municípios já haviam votado pela autonomia nessse momento. É por isto que o número de municípios votantes, nos processos constituintes, a princípio, parece pequeno.
} 
Quadro 1. Distribuição do "sim" e do "não" para autonomia indígena-originária, por município, em percentual.

\begin{tabular}{|lcc|}
\hline \multicolumn{1}{|c}{ Municípios/departamentos } & SIM & NÃO \\
\hline Charagua/Santa Cruz & 55,7 & 44,3 \\
Charazani/La Paz & $100 / 86,6$ & $0 / 13,4$ \\
Chayanta/Potosí & $50 / 60$ & $50 / 40$ \\
Chipaya/Oruro & $100 / 91,9$ & $0 / 8,1$ \\
Curahuara de Carangas/Oruro & 30 & 70 \\
Huacaya/Chuquisaca & $50 / 53,7$ & $50 / 46,3$ \\
Jesús de Machaca/La Paz & $66 / 56,1$ & $34 / 43,9$ \\
Pampa Aullagas/Oruro & $85 / 83,7$ & $15 / 16,3$ \\
Salinas de Garci Mendoza/Oruro & $68 / 75,1$ & $32 / 24,9$ \\
San Pedro de Totora/Oruro & 74,5 & 25,5 \\
Tarabuco/Chuquisaca & $86 / 90,8$ & $14 / 9,2$ \\
Villa Mojocoya/Chuquisaca & $78 / 88,3$ & $22 / 11,7$ \\
\hline
\end{tabular}

Fonte: Los Tiempos, cuaderno B. Cochabamba, Bolivia. Edición número 30. Lunes, 7 de Diciembre de 2009. Nas colunas do "sim" e do "não", os números à esquerda da barra referem-se aos resultados apurados pela fonte citada. Os números à direita da barra são os fornecidos pelo Ministério de Autonomias boliviano. Quando há apenas um resultado, ele foi transmitido por essa última fonte.

da mineração, intelectuais e camadas empobrecidas dos centros urbanos. Seu discurso é igualmente polifônico e abrange temas como multiculturalismo, direitos humanos, administração de recursos naturais, protecionismo contra o capital estrangeiro (descolonização externa), autodeterminação dos povos indígenas e camponeses (descolonização interna) e, mesmo, questões ligadas ao plantio e ao consumo da folha de coca. No artigo 5 de seu estatuto, o partido afirma reconhecer "todas as formas de organização democrática existentes na diversidade social e cultural da Bolívia", e na explicitação de seus fins e objetivos, proclama sua "adesão aos princípios multi-étnicos que conformam a raiz da nacionalidade boliviana", além de:

"Propugnar o respeito da identidade, dos costumes, e tradições das distintas culturas e etnias nativas originárias que conformam nosso país.

Fazer cumprir a Constituição Política do Estado. Defender e fazer respeitar os Direitos Humanos e sociais.

Defesa dos recursos naturais, do patrimônio de nação do território e o meio ambiente, como fatores essenciais da soberania nacional.

Defender a Democracia, as Organizações Sindicais, Organizações Indígenas, Populares e Sociais de acordo aos interesses das maiorias nacionais." (Estatuto Orgânico do Mas, art. 5,6: 1)"
Sob uma perspectiva histórica de longo alcance temporal, a aprovação dos dois tipos de autonomia - departamental e indígena - pode ser vista como o desfecho de uma longa trajetória de transformações sóciopolíticas, iniciada em 1952, quando os indígenas obtiveram formalmente a cidadania. Deve-se ressaltar que o MAS, embora não seja um partido estritamente indígena, está amplamente ligado a seus interesses. Por isso, sua ascensão, como a do Presidente Evo Morales, representa a materialização de propostas veiculadas ainda na década de sessenta pelo Movimento Katarista ${ }^{3}$. Por outro lado, o MAS é também, em certo sentido, um produto do processo de urbanização e escolarização que gradualmente foi modificando a condição da população rural. Se bem que as estruturas sindicais-corporativas, verticalmente hierarquizadas e permeadas por relações clientelísticas determinaram a modalidade e os limites da cidadania conferida a esses setores pelo MNR (Movimento Nacional Revolucionário) ${ }^{4}$, durante sua longa hegemonia, parcelas cada vez maiores de

\footnotetext{
3 O katarismo foi um movimento encabeçado por intelectuais indígenas "urbanizados" que defendiam a manutenção dos costumes e línguas indígenas dentro das agências burocráticas estatais. Seu início data da década de 60 . O katarismo permaneceu circunscrito aos grupos indígenas andinos, remanescentes od Império Incaico, não englobando os indígenas das planícies amazônicas.

${ }^{4}$ O MNR protagonizou a Revolução de 1952, em que as antigas oligarquias da mineração foram substituídas por um regime nacional-desenvolvimentista.
} 
indígenas tiveram acesso aos serviços estatais - entre esses o sistema educacional, frequentado, até mesmo no nível universitário, por algumas das lideranças do Movimento Katarista, como Felipe Quispe Huanca e Victor Hugo Cárdenas, que tiveram formação superior em História e em Sociologia e Linguística, respectivamente. Embora o MAS não seja uma organização partidária de orientação estritamente katarista, incorporou parte de seu discurso e várias de suas temáticas no atual quadro político boliviano. Conciliando a autonomia nacional frente ao "imperialismo", uma tradicional bandeira das esquerdas, com a idéia de autonomias indígenas, conseguiu atrair um amplo e diversificado eleitorado.

Aqui, pretende-se analisar os traços descentralizadores da nova Constituição, sobretudo com relação às autonomias, assim como a trajetória e o papel do MAS no processo que culminou na aprovação da mesma Constituição. Após uma análise do etnonacionalismo e do etnicismo no caso boliviano, faremos uma análise mais pormenorizada da Constituição de 2009 para, finalmente, ponderar os possíveis rumos do Estado plurinacional boliviano.

\section{Percurso do MAS Até a Constituiç̧ão de 2009 e a Natureza do Etnonacionalismo Boliviano}

O Movimento ao Socialismo foi criado em 1999 por membros do movimento cocaleiro junto à Central Sindical Única dos Trabalhadores Campesinos de Bolívia (CSUTCB). A sigla MAS, que pertencia à "ala esquerda da direitista Falange Socialista Boliviana”, foi adotada apenas para garantir personalidade jurídica perante a Corte Nacional Eleitoral e com a intenção de modificá-la no futuro. O gérmen do MAS foi o movimento cocaleiro que surgiu no vale do Chapare, no leste do departamento de Cochabamba. A organização dos camponeses dessa zona se beneficiou inicialmente da experiência de velhas lideranças sindicais que se deslocaram do Altiplano a essa região subtropical em virtude da crise do setor minerador nos anos oitenta. Ao longo dessa década, os produtores de coca - a mais rentável das culturas desde 1960 - organizaram-se para fazer frente à política de erradicação promovida pelo governo, sobretudo a partir da Lei 1008 que criminalizou a coca por considerá-la dentro das chamadas substâncias controladas. A crescente pressão dos Estados Unidos para que o governo da Bolívia controlasse a produção de coca, em aumento desde a década de 1970 devido aos altos preços da cocaína no mercado internacional, gerou expressiva reação dos sindicatos cocaleiros, sob a alegação da coca ser um cultivo tradicional, de profundo significado cultural e social e de consumo cotidiano entre a população indígena. Os produtores de coca reagiram à estratégia de guerra montada pelo governo para a erradicação do cultivo e suas organizações foram hábeis o suficiente para conseguir apoio de vários grupos, até da Câmara de Comércio, da Igreja, Human Rights Watch, Congresso, Assembléia de Direitos Humanos e organismos internacionais.

$\mathrm{O}$ atual Presidente Evo Morales fez parte desse movimento desde seus primórdios. Nascido em uma família pobre na zona rural do departamento de Oruro, perto do lago Poopó, migrou, como tantos outros, da aridez do Altiplano rumo a regiões mais férteis e promissoras, até se assentar no Chapare, no departamento de Cochabamba. ${ }^{5}$ A partir daí, pode-se dizer que Morales foi "crescendo" dentro das estruturas sindicais do movimento cocaleiro. Em 1985, tornou-se Secretário Geral do Sindicato San Francisco, depois de ter desempenhado a função de Secretário de Desportes durante quatro anos; em 1988 chegou a dirigir a poderosa Federação do Chapare e, finalmente, as seis federações cocaleiras do país, em 1996 (Pereira, 2009). Em 1997, ele foi eleito deputado nacional com $70 \%$ dos votos da circunscrição uninominal. Como parlamentar, Morales fez denúncias acerca da militarização do Chapare e da opressão policial sofrida pelos camponeses produtores da folha, e chegou a justificar a ação armada para responder às ações repressoras do governo.

O partido desde então conduzido por Morales é, entretanto, um partido atípico, uma vez que compatibiliza interesses muito diversos entre si, apresentando, inclusive, significativas cisões internas no que se refere à sua ideologia e seu discurso. De acordo com Fabrício Pereira da Silva, os integrantes do MAS de origem urbana, o vêem como um partido de esquerda tradicional, ou seja, portando um discurso político baseado na idéia de uma sociedade dividida em classes. Os integrantes do MAS provenientes do campesinato indígena, por sua vez, o enxergam como portador de um discurso centrado em traços étnico-culturais.

No campo discursivo, é possível detectar a presença de dois tipos de ideologia presentes no MAS. A primeira, um nacionalismo étnico-cultural semelhante ao populismo russo do século XIX (narodnik,) onde "povo" significa fundamentalmente a comunidade camponesa originária ou, no caso, o Ayllu dotado de particularidades específicas e detentoras de

\footnotetext{
Morales, ainda jovem, passou a fazer parte das ligas esportivas, destacando-se na prática do futebol.
} 
valores primevos e originais da sociedade. A outra é uma ideologia de esquerda centrada na idéia de classe, distanciada de conteúdos étnicos e culturais. Seu foco discursivo centra-se na classe trabalhadora e nos sindicatos urbanos (proletariado, nas palavras de Marx). O peso relativo desses dois tipos de ideologia, junto à idéia de descolonização frente ao capital estrangeiro e ao "imperialismo", faz do discurso "masista" uma espécie de nacionalismo de esquerda heterodoxo, onde se misturam traços e

[...] referências marxistas, elementos nacionalistas de esquerda, dividindo espaço com uma ideologia indianista relativamente moderada. (Pereira, 2009: 52).

Sem embargo, é a ênfase nas dimensões étnicoculturais que seguramente fazem do MAS um partido singular, fortemente condicionado pela trajetória histórica da sociedade boliviana.

As origens mais distantes do MAS estão na formação das seis federações sindicais de cocaleiros do Chapare que deram origem, em 1992, à Coordenadora das Federações do Trópico de Chapare, a qual se tornou a principal força de oposição à Nova Política Econômica (NPE) implementada na fase das reformas neoliberais a partir do fim dos anos 80 . De fato, as raízes mais longínquas estão na Central Sindical Única dos Trabalhadores Campesinos de Bolívia (CSUTCB). Esta organização sindical, formada em 1979, foi o principal veículo de contestação e reivindicação das manifestações identitárias do sindicalismo indígena-camponês. Como foi analisado e discutido por Deborah J. Yashar (2005), estruturas sindicais do tipo da CSUTCB serviram como espaços políticos associativos para que as comunidades indígenas, transcendendo o âmbito de suas localidades, pudessem construir uma identidade comum. $\mathrm{O}$ fato dos sindicatos serem formalmente organizações de caráter moderno, mas constituídos internamente com base em estruturas tradicionais, contribuiu para a formulação de um discurso anti-homogeneizante e anti-elite fora dos padrões da esquerda convencional.

Contra esse pano de fundo, o MAS surge da necessidade de se ter um partido político orgânico que representasse o conjunto do movimento sindical sem dele se autonomizar, dando-lhe o caráter de uma conformação política orgânica não desvinculada de suas bases sociais. Daí surge a tese do instrumento político, uma proposta oriunda da CSUTCB e dos cultivadores de coca "[...] que consistia em fundar um tipo de "braço político" dos sindicatos campesinos." (Stefanoni, 2005: 57).

A idéia de instrumento político seria encampada posteriormente pelo próprio MAS, devido à diversidade de focos discursivos por ele articulados e ao fato de ele próprio ser, em alguma medida, produto deste tipo peculiar de organização sindical, no sentido em que acoplava estruturas sociais em larga medida tradicionais e instituições típicas das sociedades modernas. Num quadro marcado pela crise dos partidos tradicionais, a Lei de Participação Popular (LPP), de 1994 e a Lei de Descentralização, de 1995, convergiram também para fazer do MAS uma espécie de "escoadouro" de uma pluralidade de reivindicações. As regras do código eleitoral, por sua vez, estimularam a partidarização de uma diversificada gama de movimentos reivindicatórios, incluindo aqueles trabalhistas das zonas urbanas e da mineração, e também dos movimentos indígenas (nacionalistas ou não) oriundos das distintas zonas ecológicas do território boliviano:

Tais reformas fortaleceram a tese do instrumento político, que já estava em discussão - e teriam favorecido seu sucesso posterior (Van Cott, 2005). Convocou-se, para março de 1995, em Santa Cruz, o Primeiro Congresso sobre Terra, Território e Instrumento Político, do qual participaram a Central Sindical única de Trabalhadores Camponeses da Bolívia (CSUTCB), Confederação Sindical de Colonizadores da Bolívia (CSCB), Federação Nacional de Mulheres Camponesas Bartolina Sisa (FNMCB-BS) e Confederação de Povos Indígenas do Oriente Boliviano (CIDOB). Nele foi aprovada a formação da Assembléia pela Soberania dos Povos (ASP), um "instrumento político dos povos originários", que não foi aceita pela Corte Nacional Eleitoral (CNE), o que obrigou seus integrantes a participar de eleições no interior da Esquerda Unida (IU), em 1995 e 1997. Uma questão a ser feita é o porquê de se formar nesse momento expressamente um instrumento $\mathrm{e}$ não um partido. (Pereira, 2009:59-60)

Já no ano de 2002 houve um momento decisivo para o MAS. Nas eleições presidenciais desse ano o partido conseguiu alcançar o segundo lugar, com 20,94\% dos votos, contra $22,46 \%$ de Sanchez de Lozada. A partir de então, o MAS começa a receber uma adesão cada vez maior de setores operários urbanos, profissionais liberais e, até mesmo, de parcelas do pequeno e médio empresariado. $\mathrm{O}$ fortalecimento do MAS foi fruto do caráter policlassista de sua base e de um discurso no qual se destaca a crítica ao modelo neoliberal e ao imperialismo, junto à promoção de identidades étnicas. Nesse sentido, a ideologia "masista" conjuga um nacionalismo de esquerda tradicional com a revitalização daquilo que foi, "naturalmente", o contexto cultural originário, 
profundo e imprescindível da nação: a comunidade indígena.

A partir de 2002, o MAS realizou de forma bem mais articulada uma conexão entre política das ruas e política parlamentar. A primeira passou a ser uma força de mobilização social capaz de legitimar sua atuação no segundo cenário e, ao mesmo tempo, servir como instrumento de pressão, à medida que crescia o escopo institucional do partido. Dessa forma, o MAS chegaria à presidência em 2005, com uma votação de $52 \%$ para seu candidato Evo Morales, reeleito, em 2009, com um porcentual ainda maior.

O MAS, articulando suas raízes indianistas, nacionalistas e classistas, foi um fator fundamental na condução e formulação da atual Constituição política, além de um instrumento de renovação no tradicional quadro partidário, incapaz de absorver os novos tipos de demandas que se intensificaram na década de 1990 e inícios do século XXI. Observa-se na Bolívia aquilo que, segundo Robert Dahl, acontece quando determinadas camadas de uma população se deparam com uma inclusão política mais alargada e com maiores oportunidades de participação na vida política nacional. A tendência, nesses casos, é a que os partidos anteriormente mais relevantes percam representatividade. Trata-se, então, do deslocamento do sistema de representação política no sentido de uma maior democratização. Não se quer dizer com isso que o fortalecimento do MAS seja, por si só, o catalisador dessa tendência, mas sugerir apenas que ele cumpre um papel parecido ao descrito por Dahl em sociedades antes dominadas por aristocracias tradicionais:

Quando o sufrágio vai além dos notáveis e de sua clientela, os velhos partidos e facções baseados principalmente nas relações sociais entre os notáveis - em laços familiares, de classe, residência, estilo de vida e tradição- são substituídos ou suplementados por partidos mais eficazes em atrair as classes médias. (Dahl, 1997: 44)

Embora, aqui não se trate necessária e estritamente da ascensão de classes médias contra uma antiga base social estamental, o MAS parece ser o resultado de uma dinâmica sócio-política bastante semelhante. Ele é o formato partidarizado de um emaranhado de setores sociais que, como já foi dito, abarca desde o campesinato indígena tradicional até classes médias urbanas, passando por setores operários da mineração e camadas populares urbanas que têm como denominador comum a rejeição generalizada aos velhos partidos e a suas formas de conceber e fazer política. Dessa forma, o MAS pôde funcionar, na Assembléia Constituinte, como um instrumento político mediador entre as demandas veiculadas por setores da situação e da oposição. Ao coligar-se com setores moderados das organizações indígenas e aceitar deliberar com os Comitês Cívicos Pró-Santa Cruz, o partido assumiu, em alguma medida, a condução das negociações, e conseguiu isolar as vertentes mais radicais, contribuindo, assim, para que as querelas regionais e étnicas se processassem através das "regras do jogo". O papel desempenhado por Evo Morales, nesse processo, foi crucial:

No despertar de sua impressionante vitória, Morales demonstrou admirável energia, comparecendo em diversas constituintes em um aparente esforço de reconciliação nacional. Ademais, ele viajou para Santa Cruz para se encontrar com o Comitê Cívico Pró-Santa Cruz, reconhecendo Santa Cruz como o motor do desenvolvimento nacional, assim como o local de nascimento do movimento por autonomia regional. (St. John, 2006: 1)

Ao mesmo tempo neutralizou e enfraqueceu as organizações que promoviam projetos nos quais se abriam brechas capazes de colocar em risco a unidade do Estado boliviano. Nessa mesma linha, se explica a hostilidade ao MAS por parte do CONAMAQ (Conselho Nacional de Ayllus e Markas do Qullasuyu), que defendia, antes do que um Estado boliviano com faces indígenas, a formação de um Estado índio. Esta organização foi fundada em 1997 e representa os Ayllus dos Aymarás, Quéchuas e Urus dos departamentos de Potosí, Chuquisaca, La Paz e Cochabamba. Ela é uma organização que questiona não apenas a histórica negação das estruturas comunitárias do campesinato indígena, mas também a própria estrutura territorial e administrativa do atual estado boliviano. Os setores que lhe dão suporte, na sua maioria se encontram nas comunidades do Altiplano e tendo sido menos incorporadas pelo estado mantiveram em um maior grau as suas estruturas tradicionais internas. A CSUTCB parece ter exercido muito mais influência nos processos constituintes que o CONAMAQ. O último, ao defender a idéia de reconstituição do Qullasuyu (mais próxima do Katarismo radical) e negar diálogo com a oposição, deu tons demasiadamente separatistas aos movimentos indígenas, perdendo boa parte de sua influência para a CSUTCB, que defendia um Estado com uma face indígena e não um estado totalmente indígena:

O fato de a fração do MAS na Assembléia Constituinte ter rejeitado a demanda da CONAMAQ de assentos reservados no Parlamento foi uma das principais razões desta organização declarar que não apóia o trabalho da Assembléia Constituinte no dia 4 de agosto de 2007. Ela se retirou da Assembléia Constituinte e baixou 
a Wiphala ${ }^{6}$ do Teatro Gran Mariscal, onde a assembléia mantinha seus encontros. (SchilingVacaflor, vol.4: 4)

É verdade que o CONAMAQ, não obstante o seu radicalismo, foi importante na formação de uma identidade indígena transversal aos diversos grupos étnicos. De forma paradoxal esta organização teve importante papel no estabelecimento da idéia de comunidade originária no estabelecimento do Pacto da Unidade, em 2004, na cidade de Camiri, Departamento de Santa Cruz. Pode-se dizer que o Pacto da Unidade foi uma tentativa de construção, bem sucedida em alguma medida, de uma identidade indígena mais abrangente, que não estivesse limitada a grupos indígenas específicos desta ou daquela região e que, ao mesmo tempo, deixasse espaço para a expressão das especificidades. Sob esse ângulo, a pauta hoje dominante representa, tanto uma continuidade, como um relativo distanciamento do projeto étnico do nacional-desenvolvimentismo. Em relação ao território boliviano como um todo, a identidade indígena é assim firmada independentemente do pertencimento a um Ayllu ou "comunidade originária" - um reconhecimento explicito da elevada exposição e participação da população indígena na sociedade moderna, bem como do sucesso da socialização nos valores da nacionalidade boliviana empreendida pela escola pública rural ao longo da fase nacional desenvolvimentista.

Esta é a ideia de nação indígena que, de acordo com Almut Schiling-Vacaflor, o CONAMAQ intentou construir junto ao pacto da unidade. Apesar de defender a reconstituição do Qullasuyu (modelo de organização política exclusiva dos indígenas do altiplano), Schiling-Vacaflor afirma que o CONAMAQ tentou se aproximar da CIDOB (Confederação dos Índios do Oriente Boliviano), tendo como objetivo a articulação de uma nação indígena mais ampla, uma vez que membros da própria CIDOB, assim como da APG (Assembléia dos Povos Guaranis), já haviam colocado reparos à institucionalização dos Ayllus, afirmando que essas unidades não faziam parte da experiência dos indígenas do oriente boliviano. Até certo ponto, o projeto do CONAMAQ obteve sucessos, uma vez que o Pacto da Unidade estabeleceu que não apenas os Ayllus, mas todas as formas organizacionais e administrativas indígenas obteriam status de "comunidade originária", não importando a língua ou a região à qual pertenciam. Nesta medida, pode-se dizer que o nacionalismo indígena do CONAMAQ, obteve alguns êxitos

${ }^{6}$ Bandeira indígena significativos, assim como vascularizou os diversos grupos étnicos em uma mesma orientação dual, no sentido de Anthony D. Smith, a recuperação de um passado, visando a criação de um futuro, em boa medida inédito:

Esta orientação dual - para o futuro político e o passado cultural - é o tema de qualquer exame dos principais traços e tendências na criação das nações no mundo moderno. (Smith, 1988: 152).

Deve-se lembrar que existem profundas diferenças entre os grupos étnicos da serra andina e da planície amazônica, a começar pelo fato de os primeiros serem camponeses e os segundos, na maioria dos casos, caçadores-coletores. Historicamente, estes grupos eram bastante isolados uns dos outros, mantendo contatos esporádicos entre si. Todavia, a igreja católica e a evangélica estabeleceram espaços de ligações trans-comunitárias que viriam a engendrar esferas associativas e políticas mais amplas. Enquanto os grupos andinos construíam seus espaços associativos a partir das estruturas sindicais controladas pelo Estado e nas Universidades, os orientais o fizeram junto a Igrejas de diversas denominações. Sendo assim, o peso da autoridade estatal não se fez sentir sobre eles da mesma forma que sobre os grupos andinos. A repressão aos movimentos indígena/ sindicais, particularmente intensa durante o regime de Banzer, não atingiu as planícies amazônicas, nem as organizações dos povos indígenas orientais. A mais expressiva dessas organizações foi a Confederação de Indígenas do Oriente Boliviano (CIDOB). O germe dessa Confederação nasceu nas organizações intra e intercomunais desenvolvidas entre os Izoceños-Guaranis, às quais se juntaram outras mais tarde. $\mathrm{O}$ encontro fundador da CIDOB contou com representantes de povos indígenas tais como: Izoceños-Guaranis, Guaraios, Ayoreos e Chiquitanos. Fundamental para essa articulação foi o trabalho de sociólogos e antropólogos da ONG "Apoio para o Campesino Indígena do Oriente Boliviano”, os quais, com experiência adquirida no contexto peruano, ajudaram no estabelecimento de redes de contato entre os povos indígenas amazônicos e chaqueños.

Outra organização menos expressiva, mas igualmente importante foi a Central de Povos Indígenas do Beni (CPIB). Esta se tornaria uma das principais organizações afiliadas à CIDOB . Colocando-se contra a idéia de que os indígenas do Beni eram insignificantes em sua expressão e que os poucos habitantes ali existentes não passavam de bárbaros, os organizadores da CPIB, com apoio da CIDOB, foram responsáveis pela "Marcha Indígena pelo Território e pela dignidade", realizada 
em agosto de 1990. Na ocasião, grupos indígenas do oriente boliviano saíram de Trinidad (capital do departamento de Beni) e percorreram a pé o trajeto até La Paz para entregar ao governo uma série de demandas e reivindicações relacionadas à terra e ao território. Embora utilizem o termo "comunidades originárias", os indígenas orientais não têm o Ayllu como unidade social e territorial básica. No plano simbólico, há também grandes diferenças no eixo ocidente-oriente. Os heróis trazidos ao imaginário popular não são os mesmos, e não se vê a Wiphala ${ }^{7}$ tremular entre suas fileiras. Os indígenas orientais, em geral não almejam a inter-penetração de seus costumes às estruturas administrativas e políticas do estado moderno, como os grupos ocidentais, que defendem a manutenção de seus costumes dentro de sindicatos, por exemplo, além de aproximarem o discuso étnico do discurso classista (campesinato e mineração). Os orientais, por sua vez, demandam do estado apenas a preservação de seus territórios contra a ação de fazendeiros, madeireiros e posseiros. Desta forma os grupos andinos representados pelo CONAMAQ, e principalmente pela CSUTCB têm objetivos mais próximos do moderno etno-nacionalismo. Como afirma Gellner:

O nacionalismo é primariamente um princípio político, que sustenta a idéia de que as unidades políticas e nacionais deveriam ser congruentes. $\mathrm{O}$ nacionalismo como um sentimento, ou como um movimento, pode ser melhor definido nos termos deste princípio. O sentimento nacionalista é a sensação de raiva gerado pela violação do princípio, ou a sensação de satisfação gerado pela sua implementação. Um movimento nacionalista é aquele conduzido por um sentimento deste tipo. (Gellner, 1983: 1).

Os grupos amazônicos teriam um discurso mais próximo do etnicismo pré-moderno, segundo a definição de Anthony D. Smith. Para o autor, há grandes diferenças entre o etnicismo pré-moderno e moderno. O primeiro se constituiria a partir de cânones fora da modernidade, como por exemplo, a história oral. O segundo, por cânones modernos, situados muitas vezes no campo científico, como: a Filologia, a Antropologia e mesmo a Arqueologia. O fato de não haver uma inteligentsia moderna de peso (como ocorre entre os grupos defensores do Ayllu), composta por intelectuais urbanizados, por detrás dos movimentos indígenas orientais, torna seu discurso identitário mais próximo do etnicismo antigo.

\footnotetext{
Bandeira multicolor representando as nações indígenas da região andina.
}

Entretanto seria possível afirmar que o Pacto da Unidade, ao definir todas as comunidades como município e "comunidade original", independente de língua e etnia, e tendo direito a eleger, por suas próprias leis e costumes, representantes para os legislativos departamentais e nacionais, colocou todos os grupos étnicos em um contexto nacionalista, ou etno-nacionalista mais próximo do descrito por Gellner, uma vez que é estabelecida a congruência entre território, política e cultura. Os territórios etnonacionais só não são estabelecidos de forma contínua devido à balcanização ${ }^{8}$ do país, tendo que ser implementado o princípio nacionalista gellneriano nos níveis municipais. Deve-se lembrar que um município Aymará, por exemplo, faz parte da nação Aymará mais ampla, não importa em qual departamento esteja localizado, seja La Paz, Oruro, ou Santa Cruz. ${ }^{9}$

\section{A Constituição de 2009}

A idéia de Constituição nos seus moldes modernos remete à vontade de uma determinada população, dentro de um determinado território, de reger-se e administrar-se tendo como base um texto escrito. A Constituição aprovada em 2009 representa, para o variado quadro linguístico-cultural da sociedade boliviana, a passagem de um universo pluricultural para um universo plurinacional. $\mathrm{O}$ primeiro artigo constitucional já deixa clara esta situação quando diz que:

Bolívia se constitui em um Estado Unitário Social de Direito Plurinacional Comunitário, livre, independente, soberano, democrático, intercultural, descentralizado e com autonomias. A Bolívia se funda na pluralidade e no pluralismo político, econômico, jurídico, cultural e linguístico, dentro do processo integrador do país. (Bolívia, 2009: 2)

O país é um Estado-nação que, não é povoado apenas por diversas culturas, mas diversas nacionalidades, de forma que a nova Constituição deve conciliar um lastro liberal moderno com formas tradicionais e comunitárias de administração, o que representa, em alguns aspectos (como o da plurinacionalidade), um rompimento com o modelo constitucional e ideológico implementado pelo partido MNR em 1952. Um

\footnotetext{
${ }^{8}$ Por balcanização entende-se a fragmentação da distribuição territorial de uma ou mais etnias.

${ }^{9}$ Com a migração da região andina para a oriental, em função das crises do setor mineratório, muitas comunidades indígenas andinas foram rearticuladas nas terras amazônicas.
} 
modelo em que o elemento "classe" era o principal eixo norteador ideológico. Note-se que a definição do caráter plurinacional ocupa uma posição central no primeiro artigo constitucional. Pode-se dizer que o texto da nova Carta Magna, antes de ser apenas a expressão de uma "luta pelo reconhecimento", deflagrada por grupos e movimentos étnicos e regionais, é um arcabouço normativo que busca mitigar os conflitos decorrentes da incorporação desses grupos à vida política nacional, no sentido de refundar uma nova nacionalidade. Na Bolívia, o que se verifica é a intensificação de movimentos de caráter nacionalista, na medida em que as estruturas do Estado se modernizam e passam a abranger territórios e populações antes negligenciados. A ampliação do sistema educacional expôs vários segmentos da população que antes sequer tinham cidadania formal a um novo contexto de modernização instrumental. ${ }^{10}$

$\mathrm{O}$ advento do Movimento Katarista (cujo cerne discursivo seria mantido também na luta contra o estado neo-liberal pós 85) é, em alguma medida, resultados desta maior presença do Estado (sobretudo nas áreas rurais). O katarismo, arquitetado por intelectuais indígenas "urbanizados" esforçou-se para que fossem mantidos, dentro das estruturas sindicais, as línguas faladas e os costumes praticados nas comunidades rurais, conectando, assim, instituições rurais tradicionais às organizações estatais modernas. Ao entender o termo "povo" enquanto comunidade rural e não como massas concentradas em centros urbanos, o discurso katarista e seu sucedâneo institucional traduzido no Pacto da Unidade ${ }^{11}$ construíram um tipo de identidade semelhante àquela que foi defendida pelos populistas russos (narodniks) do século XIX. Estes viam nas comunidades rurais "originárias" (mir) e suas estruturas jurídicodeliberativas (obschina) o fundamento cultural, social, político e econômico de sua pátria. ${ }^{12}$ Esta forma de apelo popular, de tipo narodnik, aparenta, em certa

\footnotetext{
${ }^{10}$ Por modernização instrumental me refiro á modernização das estrutura técnicas do estado, e não á "modernização ideológica", como a chegada de valores republicanos e democráticos.

${ }^{11}$ O Pacto da Unidade foi um acordo estabelecido em 2006, na cidade de Camiri, no departamento de Santa Cruz que, estabelecia que toda comunidade indígena, na importa de qual grupo étnico ou região, deveria se reconhecida como "comunidade originária", podendo tornar-se um município.

${ }^{12}$ Os populistas defendiam a idéia de que as comunidades camponesas eslavas não conheciam a propriedade privada. Desta forma, embora Lênin fosse contrário á idéia de manutenção das "virtudes" do mir, pode-se dizer que os populistas russos, em alguma medida, pavimentaram os caminhos para o socialismo Leninista, ao afirmar que a Rússia não precisaria passar pelo tipo inglês de industrialização e gerar uma robusta classe revolucionária. As bases sociais para a eliminação da propriedade privada estariam no campesinato tradicional.
}

medida, ser algo inédito na América Latina, onde tradicionalmente o apelo ao "povo" se direciona a densas massas urbanas (marca inconfundível dos regimes populistas latino-americanos). $\mathrm{O}$ discurso katarista, assim, defendeu a idéia de um Estado que, embora modernizado, mantivesse os valores da antiga comunidade rural.

O traço mais marcante da nova Constituição talvez seja a conexão entre direitos universais e abstratos centrados na idéia de indivíduo, e direitos tradicionais, comunitários, centrados na idéia do coletivo. É interessante notar que os princípios básicos da organização liberal do Estado não são negados, apenas acrescentados por outras noções de pessoa jurídica; como aponta Mota:

Neste sentido, as principais inovações presentes na Constituição, podem ser sobremaneira sentidas no que se refere às autonomias e à livre determinação; à concepção de pessoa jurídica mais ampla do que somente individual - onde observamos explicitamente a emergência do fenômeno que chamo de complexificação da noção de pessoa; na forte percepção de que a preservação, a forma de distribuição e os usos da Pachamama (Mãe Terra), bem como dos recursos naturais bolivianos são vistos como essenciais para o desenvolvimento integral do país; e, por fim, de uma forma democrática participativa popular ampliada. (Mota, 2009: 145)

Estas noções se materializam através da criação dos municípios indígenas dentro dos departamentos, que se tornam instâncias administrativas com o mesmo status dos municípios não-indígenas. A municipalização das "comunidades originárias" representa a descolonização interna do Estado boliviano, tema da mais alta importância na elaboração da nova Constituição. A descolonização seria, na verdade, o direito proporcionado às comunidades, ou conjunto de comunidades, de administrarem os recursos naturais circunscritos em seus territórios a partir de seu ordenamento jurídico tradicional, assim como a eleição de autoridades para cargos "públicos" de acordo com seus sistemas políticos originários ${ }^{13}$.

\section{A Constituição e as Autonomias Etnonacionais}

O artigo 269 da Constituição, primeiro da terceira parte intitulada "Estrutura e organização territorial

\footnotetext{
${ }^{13}$ Apesar de a Constituição fornecer mais dois tipos de autonomia (regional e municipal), elas não serão analisadas neste estudo, devido ao fato de ele se centrar nas autonomias indígenas e departamentais.
} 
do estado", representa uma inovação face aos textos constitucionais anteriores, precisamente por incluir na configuração territorial da Bolívia, além dos departamentos, províncias e municípios, os territórios indígenas originários campesinos. (Bolivia, 2009: 48) $\mathrm{O}$ direito à autodeterminação, ao menos nas esferas "municipais", está assegurado aos povos indígenas, sobretudo pelo artigo 289, o qual estabelece que:

A autonomia indígena originária campesina consiste no auto-governo como exercício da livre determinação das nações e dos povos indígena-originário campesinos, cuja população compartilha território, cultura, história, línguas, e organização ou instituições jurídicas, políticas, sociais e econômicas próprias. (Bolivia, 2009: 51)

As bases territoriais das autonomias indígenas originárias camponesas, os requisitos para a sua constituição, assim como a forma pela qual deverão ser superados possíveis conflitos de limites entre distritos municipais e o território de comunidades originárias em formação, são especificados nos seguintes artigos:

Artigo 291. I. São autonomias indígena-originárias campesinas os territórios indígena-originário campesinos, e os municípios, e regiões que adotam tal qualidade de acordo ao estabelecido nesta Constituição e na Lei.

II. Dois ou mais povos indígena-originários campesinos poderão conformar uma só autonomia indígena-originário campesina. (Bolivia, 2009: 51)

Artigo 292. Cada autonomia indígena-originário campesina elaborará seu Estatuto, de acordo com suas normas e procedimentos próprios, segundo a Constituição e a Lei. (Bolivia, 2009: 51)

Artigo 293. I. A autonomia indígena baseada em territórios indígenas consolidados e naqueles em processo, uma vez consolidados, se constituirá pela vontade expressada de sua população com consulta em conformidade a suas normas e procedimentos próprios como único requisito exigível.

II. Se a conformação de uma autonomia indígenaoriginária campesina afetar limites de distritos municipais, o povo ou nação indígena-originário campesina e o governo municipal deverão acordar uma nova delimitação distrital. Se afetar limites municipais, deverá seguir-se um procedimento ante a Assembléia Legislativa Pluri-nacional para a sua aprovação, prévio cumprimento dos requisitos e condições particulares que assinale a Lei.
III. A Lei estabelecerá requisitos mínimos de população e outros diferenciadores para constituição de autonomia indígena-originária campesina.

IV. Para constituir uma autonomia indígenaoriginária campesina cujos territórios se encontrem em um ou mais municípios, a lei assinalará os mecanismos de articulação, coordenação e cooperação para o exercício de seu governo. (Bolivia, 2009: 52)

Artigo 296. O governo das autonomias indígenaoriginária campesinas se exercerá através de suas próprias normas e formas de organização, com a denominação que corresponda a cada povo, nação, ou comunidade, estabelecidas em seus estatutos e em sujeição à Constituição e à Lei. (Bolivia, 2009: 52)

Enquadradas no marco constitucional, as competências das autonomias indígena-originárias campesinas estão definidas no artigo 304 que, num conjunto de competências, estabelece como exclusivas as seguintes:

1. Elaborar seu Estatuto para o exercício de sua autonomia conforme a Constituição e a Lei.

2. Definição e gestão de formas próprias de desenvolvimento econômico, social, político, organizativo e cultural, de acordo com sua identidade e visão de cada povo.

3. Gestão e administração dos recursos naturais renováveis, de acordo com a Constituição.

12. Criar e administrar taxas, patentes e contribuições especiais no âmbito de sua jurisdição de acordo com a Lei.

13. Administrar os impostos de sua competência no âmbito de sua jurisdição.

14. Elaborar, aprovar e executar seus programas de operações e seu pressuposto.

15. Planificação e gestão da ocupação territorial.

21. Participar, desenvolver e executar os mecanismos de consulta prévia, livre e informada relativos à aplicação de medidas legislativas, executivas e administrativas que os afetem.

22. Preservação do hábitat e da paisagem, conforme a seus princípios, normas e práticas culturais, tecnológicas, espaciais e históricas. 
23. Desenvolvimento e exercício de suas instituições democráticas conforme a suas normas e procedimentos próprios.

II. As autonomias indígena-originário campesinas poderão exercer as seguintes competências compartilhadas:

2. Participação e controle no aproveitamento de áridos.

3. Resguardo e registro dos direitos intelectuais coletivos, referidos a conhecimentos de recursos energéticos, medicina tradicional e germoplasma, de acordo com a Lei.

4. Controle e regulação das instituições e organizações externas que desenvolvam atividades em sua jurisdição, inerentes ao desenvolvimento de sua institucionalidade, cultura, meio ambiente e patrimônio cultural. ${ }^{14}$

A nova Constituição atende, em boa medida, as demandas feitas pelo Pacto da Unidade que, em conjunto com o MAS, foram colocadas na Assembléia Constituinte. A administração de bens como terra, saúde e educação, além da consulta às comunidades "originárias" em caso de exploração de bens naturais dentro de sua jurisdição, são todos direitos garantidos pela Constituição. Os acordos estabelecidos no Pacto da Unidade pelas comunidades e nações indígenas afirmavam que as autonomias indígenas deveriam fazer parte da divisão política e administrativa do país, o que ocorreu. As comunidades indígenas são uma das quatro instâncias político-administrativas do país. A possibilidade de mais de um povo indígena compor um município indígena também se tornou uma realidade. A demanda por um estado unitário pluri-nacional, em certa medida, também foi atendida. O interessante é que a descentralização das territorialidades étnicas e campesinas foi feita pela via cantonal/municipal, e não pela via provincial/departamental, o que pode evitar conflitos no futuro. Isto por quê cada município indígena, independente de qual seja seu grupo étnico específico pode exercer seu auto-governo em qualquer

\footnotetext{
${ }^{14}$ Além disso, as autonomias indígena-originário camponesas poderão exercer as seguintes competências concorrentes:

1. Organizaç̃ão, planificação e execuşã̃o de planos, programas e projetos de educação, ciência, tecnologia e investigação, no marco da legislação do Estado.

2. Conservaçẫo de recursos florestais, biodiversidade e meio ambiente.

3. Sistemas de irrigação, recursos hidricos, fontes de água e energia, no marco da politica do Estado, ao interior de$$
\text { sua jurisdição. }
$$$$
\text { 4. Construção de sistemas de micro-irrigação. }
$$$$
\text { 5. Construção de caminhos vicinais e comunais. }
$$$$
\text { 9. Controle e monitoramento sócio-ambiental das atividades hidrocarboriferas e mineiras que se desenvolvam em su }
$$$$
\text { jurisdição. }
$$

10. Sistemas de controle fiscal e administração de bens e serviços. Bolivia, 2009: 57-58.
}

departamento. Por exemplo, um município Aymará pode se auto-governar tanto no departamento de La Paz (seu suposto lar original) ou no de Santa Cruz, para onde muitos Aymarás migraram em busca de melhores condições de vida. Como afirma Gellner, quando faz uma série de recomendações para solucionar o problema das clivagens étnicas

Estas são as únicas recomendações gerais que se pode fazer: a preferência pela estabilidade, evitar a desestabilização sem causa considerável e sem provisão para uma passagem ordenada para um regime sucessor; afluência; centralização das maiores funções de manutenção da ordem e a cantonização das maiores funções sociais; pluralismo cultural e desfetichização da terra. (Gellner, 1997: 108).

Entretanto, as demandas das organizações indígenas foram apenas parcialmente atendidas, uma vez que elas reclamavam um estado unitário onde as principais instâncias descentralizadoras fossem os municípios. Isto porque as autonomias propostas pelas organizações da "meia-lua", que visavam descentralização por via departamental, também foram aprovadas. Se o pluralismo jurídico intra-departamental vai gerar ou não conflitos de maior monta (sobretudo nos departamentos orientais, que concentram oposição ao MAS) ainda é algo que apenas o futuro dirá, pois ainda é muito cedo para fazer qualquer constatação a esse respeito. A questão é que as demandas por autonomia dos povos indígenas foram, em ampla medida, atendidas, tendo apenas que conviver lado a lado com outras instâncias autonômicas e administrativas.

Também é verdade que o "universo" social boliviano de traços mais indígenas e tradicionais e aquele de traços mais modernizados, mais mestizocriollo, não formam esferas sociais separadas e estanques. Pelo contrário, elas estão altamente inter-penetradas, de forma que muitos "originários" estudam ou trabalham nas cidades e localidades fora de seus municípios. Nesta medida pode haver um choque de valores que acarrete em sérios problemas, pois as formulações modernas e liberais do que seja um indivíduo podem se chocar com as tradicionais.

Um exemplo desses possíveis problemas diz respeito a questões de gênero. A mulher e como é interpretado seu papel na estrutura social é um exemplo dos mais emblemáticos. Uma mulher originária de um município indígena, que tem algum tipo de atividade (estudo, trabalho) fora de sua comunidade, pode interpretar a maneira através da qual é vista dentro de um quadro valorativo tradicional, como atrasada, retrógrada e mesmo pré-conceituosa. $\mathrm{O}$ choque de valores, principalmente 
dos estratos mais jovens da população indígena com os mais velhos pode vir a ser um grande problema, visto que novas figurações sociais podem surgir do contato entre "originários" e "não-originários". Uma grande pluralidade de sistemas ordenadores baseados principalmente na tradição corre o risco de, no futuro, gerar espécies de pequenos enclaves que venham a colidir com a forma de ordenamento mais ampla do Estado. Assim, uma questão central que fica a porvir é o choque entre os direitos universais e abstratos e os direitos tradicionais e comunitários.

\section{Conclusão}

A Constituição de 2009 traz sinais de que o encaminhamento do sistema político boliviano é no sentido de uma poliarquia, mais que de uma hegemonia fechada. Trata-se de uma etapa de um processo que começou ainda no ano de 1952, quando o MNR jogou por terra a ordem oligárquica, nacionalizou as grandes empresas mineradoras, universalizou o voto e incluiu, pelo menos formalmente, a população camponesa na esfera cidadã. Após estarem submetidos por diversos regimes corporativos e autoritários (1964-1985), os grupos indígenas reclamaram seu direito de existir, não só como cidadãos formais, mas como nações específicas. Novos partidos surgiram para preencher o "vácuo" deixado pelos partidos que dominaram a política durante a fase nacional-desenvolvimentista, o mais importante dentre eles o MAS-IPSP.

Embora a Bolívia permaneça, constitucionalmente, um Estado unitário, certamente acusa importantes traços consociacionais, em função da Carta Constitucional reconhecer a legitimidade dos modos de se fazer justiça por parte das comunidades indígenas, segundo usos e costumes, e do poder desses municípios comunais de vetar decisões tomadas a nível nacional. Desta maneira, a descentralização alcançada pelas autonomias indígenas, parece encaminhar o sistema político para um corolário mais próximo da democracia consociativa. Mas tudo isso se encontra, ainda, em aberto, uma vez que a Constituição, não obstante sua extensão, ainda é uma peça normativa genérica, cujos objetivos gerais, para serem alcançados, dependem de leis ordinárias que surgirão do parlamento, onde deve situar-se o próximo ciclo de polêmicas e embates políticos.
O sistema político boliviano orquestrado pelo MAS é, certamente, mais poliárquico entre todos quantos o precederam nesse país. Apesar de a Bolívia não ser formalmente uma federação, pode-se dizer que há uma assimetria sui generis na relação do centro com os municípios indígenas autônomos, uma vez que cada povo ou nação indígena se rege e direciona suas demandas ao poder central de acordo a seus próprios usos e costumes. Só o futuro nos dirá se a Constituição boliviana se torna um mecanismo político para que nesse país se promova a formação de uma identidade nacional capaz de superar as clivagens étnicas e regionais que podem ser uma ameaça à unidade do Estado.

\section{Referência}

Bolivia. 2009. Constitución Del Bolivia.

Dahl, Robert Alan. 1997. Poliarquia. Editora EdUSP.

Estatuto Orgânico do MAS.

Gellner, Ernest. 1997. Nationalism.

Gellner, Ernest. 1983. Nations and nationalism. Ithaca, New York: Cornell University Press.

Mota, Áurea. 2009. A nova constituição política do estado boliviano. In: J. M. Domingues e A. S. Guimarães (orgs.), A Bolivia no espelho do futuro. Belo Horizonte: Editora UFMG.

Pereira da Silva, Fabrício. 2009. Equilíbrios precários. A trajetória do Movimento ao Socialismo e seus dilemas. In J. M. Domingues e A. S. Guimarães(org), A Bolívia no espelho do futuro. Belo Horizonte: Editora UFMG.

Schiling-Vacaflor, Almut. Indigenous identities and politico-juridical demands of CSUTCB and CONAMAQ in the constitutional change process of Bolivia. T'inkazos, 4.

Smith, Anthony D. 1988. The Ethnic Origins of Nations. Blackwell Publishing.

St. John, Ronald Bruce. 2006. Evo Morales No Che Guevara. Global Politician.

Stefanoni, Pablo e Do Alto, Hervé. 2005. De la coca al Palacio. Una oportunidad para la izquierda indígena.

Van Cott, L. Donna. 2005. From Movements to Parties in Latin America: the evolution of ethnic politics. Cambridge University Press.

Yashar, Deborah J. 2006. Contesting citizenship in Latin America: the rise of indigenous movements and the post-liberal challenge. Cambridge: Ed. Cambridge University Press. 